\title{
Roosevelt y Franco
}

JAVIER TUSELL

En apariencia la cuestión referente a las relaciones entre FDR y Franco puede ser resuelta de una manera muy simple: sus ideales politicos eran radicalmente antitéticos, incluso en cierta manera más antitéticos que los de Roosevelt y Mussolini, por ejemplo. Aunque Franco experimentó durante algún tiempo en su vida la tentación del fascismo, en realidad era un dictador militar conservador y católico; para él el liberalismo democrático, que identificaba con la masonería, no era sólo una doctrina inaceptable sino que, además, conducía inevitablemente al comunismo. En cierta manera sus conceptos políticos eran anteriores a la democracia, mientras que el fascismo fue una doctrina posdemocrática. Roosevelt, en cambio, representó la adecuación del ideal democrático al reto experimentado por la Humanidad en la dificil coyuntura de los años treinta. Sus mundos, por tanto, no eran sólo antitéticos sino, sobre todo, lejanos, por lo que no puede extrañar que no existiera entre ellos un posible mínimo de entendimiento.

Pero la cuestión no se agota en este punto. La relación entre ambos resulta de interés porque permite plantearse el problema de la manera en que el presidente norteamericano trató de llevar a la práctica sus ideales de política exterior mundial en lo que se refiere a una nación de segunda fila y que, por tanto, no estuvo más que muy ocasionalmente entre sus preocupaciones fundamentales. La relación entre España y los Estados Unidos a partir del momento en que Franco empezó a desempeñar un papel político relevante en el primer país sirve para precisar la actitud de Roosevelt en relación con un conflicto que podia afectar a la paz mundial, respecto de su visión de la neutralidad o una posible intervención en una contienda interna en que se ventilaba el futuro de la democracia en un país o su posición sobre quienes, durante la Segunda Guerra Mundial, fueron por lo menos benevolentes respecto del Eje y su 
posible subsistencia a partir de 1945. Además, en el fondo, en esta relación se plantean cuestiones de primera importancia que todavía subsisten como problemas en la política exterior de toda democracia, como, por ejemplo, el empleo de los medios y los fines.

\section{ROOSEVELT Y LA GUERRA CIVIL ESPAÑOLA}

Ha habido quien ha interpretado la política norteamericana respecto de la II República española como el producto de una "neutralidad malevolente" que explicaría la indefensión del régimen cuando se produjo la sublevación de Franco en julio de $1936^{1}$. Esta interpretación, sin embargo, no parece justa. Lo demuestra el nombramiento en 1933, como embajador en España, de Claude G. Bowers, un beligerante demócrata, no profesional de la diplomacia, que en todo momento identificó a la República con el New Deal de Roosevelt de quien era amigo. En su correspondencia con el presidente norteamericano habia siempre una gran admiración por Azaña e incluso una asimilación entre algún político socialista español, como De los Ríos, y el partido demócrata norteamericano, asimilación que era aceptada por el propio ex-ministro español y que explica su nombramiento posterior como embajador en Washington. Bowers no siempre estuvo bien informado acerca de la situación española y siempre interpretó los acontecimientos con una óptica partidista. Eso explica que a menudo no fuera escuchado por el Departamento de Estado, pero, en cambio, como político importante en el partido demócrata y persona que coincidía en planteamientos fundamentales con Roosevelt fue siempre tenido en cuenta por éste ${ }^{2}$.

Para comprender la posición de Roosevelt respecto de la guerra civil española hay que partir no sólo de esa simpatía acerca de la República, sino también del momento que se vivia en los Estados Unidos. La supuesta pasividad del presidente norteamericano respecto de la victoria

' LITLLE, Douglas, Malevolent neutrality. The United States, Great Britain and the origins of the Spanish civil war. Cornell University Press, 1985, 290 págs.

2 Véase G. Bowers, Claude, My mission to Spain. Watching the rehearsal for World War II. New York, Simon and Schuster, (1954), 439 págs. La correspondencia de Bowers y Roosevelt en FDR Papers. Hyde Park, PSF, Box 69. Un juicio sobre su tarea como emba. jador, en LITTLE, Douglas, "Claude Bowers and his mission to Spain: the diplomacy of a jeffersonian democrat", en JONES P., Kenneth, Us diplomats in Europe, 1919-1941. Sta. Bárbara, ABC-Clio, 1983, págs. 129-146. 
del fascismo en España tiene que ser interpretada no desde el punto de vista de 1945, sino teniendo en cuenta que la política de «apaciguamiento" fue, en mayor o menor grado, generalizada entre las potencias democráticas hasta 1939; precisamente, como veremos, fue Roosevelt uno de los dirigentes democráticos que más dudó respecto de la política de neutralidad en el conflicto español. Por otro lado la voluntad de mantenerse alejados de los conflictos europeos no sólo estaba fundamentada en disposiciones legales de 1935 y 1946, sino también en una conciencia generalizada: incluso Hemmingway, que luego estuvo presente en la guerra española, participaba de este sentimiento. Por si fuera poco, los años de la guerra civil presenciaron un importante agravamiento de las dificultades internas del presidente norteamericano con el Congreso to que contribuyó a paralizar su acción respecto del conflicto español ${ }^{3}$.

Estas premisas sirven para explicar la posición de Roosevelt respecto de la guerra civil española ${ }^{4}$. Respecto de ella, como de la Segunda Guerra Mundial, hay que distinguir entre la posición de los diplomáticos norteamericanos en España, la posición del Departamento de Estado y la del propio Roosevelt y hay que tener en cuenta, además, la evolución de los acontecimientos que fue creando unas condiciones diversas con el transcurso del tiempo.

La posición de Bowers fue desde un principio tan entusiásticamente partidista como lo habia sido su posición respecto de la República. No propuso la intervención en los asuntos internos españoles porque eso hubiera estado demasiado lejos de la política norteamericana de la época, pero apoyó a la causa del Frente Popular de manera meridianamente clara. Para él el Eje estaba en guerra contra las instituciones legitimas españolas; la sublevación, que se había preparado desde el mismo momento de las elecciones de 1936 (una frase que Roosevelt subrayó en la carta que de él recibió) haría retroceder a España al siglo Xvı. No había peligro comunista en España y se mantenia la legalidad democrática. Lo que llama la atención de esta postura es hasta qué punto contrastaba con la del resto de los diplomáticos de países democráticos en España.

3 Dallek, Robert, Franklin D. Roosevelt and American Foreign Policy, 1932-1945. Oxford university Press, 1979, 657 págs., especialmente 530 .

${ }^{4}$ Sobre los Estados Unidos y la guerra civil española véase, desde el punto de vista española Marquina, Antonio, "Estados Unidos y la guerra de España», en "La guerra civil», Historia 16, vol. XVIII, págs. 80-89. Desde el punto de vista norteamericano GuTTMANN, Allen, American neutrality and the spanish civil war. Lexington, Heath and Co., 1968, 115 págs.; F. JAY, Taylor, The United States and the Spanish civil war. New York, Bookman Associates, 1956, 288 págs., y P. Traina, Richard, American Diplomacy and the Spanish civil war. Indiana University Press, 1968, 301 págs. 
Como los embajadores británico y francés, Bowers estuvo durante la guerra civil en territorio francés, junto a la frontera española, pero discrepó de la posición de ellos por mantener una actitud contraria al Frente Popular; a él le pareció que la no intervención era una "siniestra farsa". Con frecuencia se indignaba contra la prensa a la que acusaba de no hacerse eco más que de las atrocidades de las que eran culpables las izquierdas. Cuando las autoridades de Franco quisieron interpretar la reapertura del consulado de Bilbao como un reconocimiento de su régimen se apresuró a mantenerlo cerrado. Presentó a Roosevelt al embajador español, De los Ríos, como un amigo propio y, al final de la guerra, en enero de 1939, cuando ya era patente la victoria de Franco, describió su régimen como "hostil a los Estados Unidos, a sus líderes y a su política" ${ }^{5}$. Se puede pensar que su posición no tuvo verdadera influencia en el desarrollo de la política exterior norteamericana, pero este juicio no tendría en cuenta que fue mantenido como embajador a pesar de su actitud, tan discrepante de la británica y francesa, y que, al final de la guerra incluso recibió una nueva embajada, la de Chile, otro país gobernado por un Frente Popular. Hay que concluir, por tanto, que tuvo una indudable influencia sobre Roosevelt, como lo demuestra la correspondencia cruzada entre ambos.

En sus memorias Bowers sugiere que la posición del secretario de Estado, Cordell Hull, respecto de la guerra civil española fue de «apaciguamiento". Tal afirmación es, desde luego, exagerada, pero hubo siempre una significativa diferencia de criterio entre ambos. El propio Hull señala que Bowers no parecia darse cuenta de la necesidad de hacer todos los esfuerzos para evitar un conflicto bélico generalizado. Recuerda, además, que la política seguida respecto del conflicto español satisfizo al mismo tiempo a los aislacionistas, que veian alejarse con ella el peligro de que los Estados Unidos se involucraran en una guerra europea, y a los internacionalistas, dispuestos a colaborar con las restantes potencias democráticas y principalmente con la Gran Bretaña. Hull señala que a esa política se llegó con una velocidad y una unanimidad poco frecuentes y que, en definitiva, la guerra civil española no fue la causa del estallido de la mundial ${ }^{6}$. Todas estas afirmaciones son ciertas. En términos generales puede decirse que el Departamento de Estado siguió una política basada en el alineamiento con los principios neutralistas de

${ }^{5}$ Frus, 1939, II, pág. 716.

6 The Memoirs of Cordell Hull. New York, The Mcmillan Company, 1948, 2 vols., principalmente $479,485,513$ y 517 págs. 
la política norteamericana y con el deseo de identificarse con la política británica respecto de la guerra civil española.

Entre estos dos polos fundamentales se movió la política de Roosevelt en torno a la guerra civil española y el nuevo régimen dictatorial bajo Franco. La política seguida por los Estados Unidos estuvo, como es lógico, más cercana a la segunda opción mencionada, pero permaneció siempre la conciencia de que hubiera sido deseable intervenir de algún modo en un conflicto en el que un régimen legal había sido destruido, en parte al menos, por la intervención de las potencias fascistas. Esto explica que, aunque la actitud de Roosevelt fuera adoptada de manera temprana y con un acuerdo generalizado, en varias ocasiones estuviera en peligro de ser revocada y que, aunque se mantuvo hasta el final, resultara profundamente insatisfactoria para el mismo que la patrocinó.

Antes de que en los primeros días de agosto de 1936 el Departamento de Estado hiciera expresa una voluntad de no intervención en el conflicto español ya se había desaconsejado vender combustible a los barcos de guerra de los beligerantes ${ }^{7}$. Las instrucciones del 7 de agosto de 1936 a los representantes diplomáticos norteamericanos eludian el término "neutralidad» y tampoco hacian mención de la "guerra civil», pero prescribian una escrupulosa abstención de intervenir en los asuntos españoles. De ahí que se instruyera a Bowers en la necesidad de no participar ni siquiera en las reuniones patrocinadas por el cuerpo diplomático residente en España para lograr la paz a través de la mediación.

En este momento inicial Roosevelt parece haber estado muy preocupado por la "desafortunada y terrible tragedia» española, según escribió a Bowers, con quien no tenía inconveniente en coincidir respecto del partidismo en las interpretaciones de la prensa ${ }^{8}$, pero sobre todo por la eventualidad de que propiciara el desarrollo de un conflicto general europeo. Este es el motivo por el que se planteó la eventualidad de modificar la legislación vigente en un momento en que todavia no se había percibido el efecto contraproducente que podia tener una no intervención como la que estaban empezando a aplicar los países europeos democráticos. Las leyes de neutralidad no se aplicaban a conflictos internos de estados, de manera que Roosevelt sólo podía proponer un "embargo moral», como el que ya se había aplicado en el caso del conflicto de

\footnotetext{
7 Frus, 1936, II, págs. 437 y ss

${ }^{8}$ FDR. His personal letters, 1928-1945. New York, Duell, Sloan and Pearce, 1950, I. págs. 614-615.
} 
Etiopía; por eso calificó la venta de armas a los republicanos como «legal pero completamente antipatriótica».

En enero de 1937, para llenar este vacío legal, el Senado y el Congreso votaron, con tan solo un voto en contra, la aplicación del embargo al conflicto español, incluso vetando la venta a través de un tercer país. Esta decisión fue convertida en disposición de carácter general en el mes de mayo, también con considerable mayoria. La nueva ley de neutralidad era inflexible no permitiendo que el presidente pudiera actuar de acuerdo con las circunstancias: no se planteó la posibilidad de ayudar a un régimen legal amenazado por la subversión externa en la que colaboraran otros países. Roosevelt no quería, en estos momentos, provocar un debate que pusiera en peligro sus otras reformas, como, por ejemplo, la judicial y tampoco se sentía inclinado a solicitar poderes discrecionales en un momento en que era acusado de ser un dictador ${ }^{9}$. Pero, sobre todo, no veía los posibles peligros de una neutralidad como ésta en el caso español. Al socialista Normas Thomas partidario de la República, le aseguró que sería extremadamente peligrosa una política que intentara, en una guerra civil, discriminar ante las partes. Otras quejas surgieron en medios aislacionistas: el senador progresista Gerald P. Nye se manifestó partidario del embargo de cualquier comercio de armas excepto aquel que beneficiara a una nación americana atacada por otra que no lo fuera.

La importancia de estas quejas fue discreta en un primer momento, pero arreciaron en el verano de este mismo año cuando se hizo patente la intervención de italianos y alemanes a favor de Franco. Entonces tanto Thomas como Nye sugirieron que habia un estado de guerra entre Alemania e Italia y la República española y, por ello, pidieron la extensión del embargo de armas a esos paises. Empezó, de esta manera, a darse la paradoja de que un internacionalista como Roosevelt utilizaba argumentos no intervencionistas mientras que el aislacionista Nye estaba más dispuesto a ayudar a la República que el presidente ${ }^{10}$. Pero tan solo esta actitud motivó las primeras dudas de Roosevelt respecto a la oportunidad de la neutralidad, tal como se había practicado hasta entonces. De ahí que pidiera a Hull que se dirigiera a los embajadores norteamericanos en París y Londres preguntándoles acerca de esa posibilidad ya mencionada. La respuesta fue que el estado de guerra entre la República y las potencias fascistas no existía desde el punto de vista técnico; además

9 DALLEK, op. cit., págs. 136 y 140.

${ }^{10} \mathrm{~S}$. COLE, Wayne, Roosevelt and the isolationists. University of Nebrasca Press, 1983, 698 págs., esp. 224. 
hubiera sido necesario aplicar el embargo también a Rusia y Francia. Roosevelt a estas razones sumó la afirmación de que la ampliación del embargo podía tener como consecuencia poner en peligro cualquier intento de mediación ${ }^{11}$.

Pero, si ya en 1937 se había hecho patente que la neutralidad norteamericana favorecía sobre todo a Franco, que no tenía problemas para adquirir sus armas mientras que a la República se le cerraba el mercado norteamericano, esta situación todavía fue más evidente en 1938. En mayo Nye propuso que se levantara el embargo al Gobierno republicano. Roosevelt era ya consciente de los inconvenientes de la neutralidad norteamericana pero, al mismo tiempo, no quería que la ley de mayo de 1937 fuera revocada y seguía teniendo graves problemas respecto de la política interior. Pensó en la posibilidad de autorizar a Bowers a estar presente en la zona republicana como modo indirecto de solidarizarse con esta causa; le expresó, además, en agosto, su "tristeza" ante la política de no intervención británica y confió en que «un poco más tarde, si la situación de Checoslovaquia no termina desastrosamente pueda hacerse algún tipo de movimiento con la finalidad de, por lo menos, ayudar a la terminación de la guerra civil española" ${ }^{12}$.

En los últimos meses de 1938 y primeros de 1939 ya tanto Roosevelt como buena parte de sus colaboradores eran conscientes del error cometido respecto de la guerra civil española y de la necesidad de repararlo. En estos momentos el presidente norteamericano fue partidario de una solución negociada entre las dos partes, merced a la intervención del Vaticano o de los paises iberoamericanos, pero esta solución no llegó a fraguar fundamentalmente porque ya era demasiado tarde: la victoria de Franco, que habia dividido la zona adversaria y tenia una neta superioridad material, lo impedía. Además seguía teniendo los mismos problemas en la política interna que antes. No obstante en noviembre sometió a consulta la eventualidad de interpretar que él tenía derecho a suspender el embargo a la República. Alguno de sus colaboradores, como Ickes, era partidario de esta fórmula, pero predominó la interpretación de Hull de acuerdo con la cual sólo el Congreso podía levantar el embargo y cualquier cambio supondria "una posibilidad de complicaciones" ${ }^{13}$. En cualquier caso a fines de 1938 aunque se hubiera levantado el embargo

"The Memoirs of Cordell Hull, I, págs. 511-514.

${ }^{12}$ FDR Papers, PSF, Box 69, Roosevelt a Bowers, 31-VIII-1938.

13 The Memoirs of Cordell Hull, I, págs. 516-517; DaLLEK, op. cit., págs. 178-180. 
poco podría haber beneficiado al Gobierno republicano que ya carecía de fondos para adquirir armas.

Es necesario hacer mención, también, de un factor que en estos meses finales de la guerra jugó un papel de primera importancia respecto de la parálisis decisoria de las autoridades norteamericanas acerca de la guerra civil española: la propia división de la sociedad en torno al conflicto ${ }^{14}$. La opinión norteamericana fue claramente partidaria de la República, con sólo un $14 \%$ de franquistas; en los medios liberales e intelectuales la posición contraria a Franco era todavía más abrumadora. Sin embargo, en los Estados Unidos, como en el resto del mundo, Franco consiguió un importante apoyo entre los medios católicos. Fue precisamente este hecho el que explica que Roosevelt eludiera el planteamiento de la guerra civil española como tema de discusión en la campaña electoral de 1936, pues podía enajenarle a una parte de su electorado ${ }^{15}$. A partir de finales de 1937, después de la publicación de una carta pastoral de los obispos españoles a favor de Franco, la mayor parte de los medios católicos norteamericanos se alinearon con la causa de los sublevados; la revista The Commonweal y The Catholic Worker, donde escribía Dorothy Day, optaron por una posición más neutral. De esta manera se produjeron duras polémicas entre católicos, de un lado, y protestantes y judios, de otro, que parecieron despertar un enfrentamiento religioso infrecuente en los Estados Unidos. En realidad ni unos ni otros estaban muy informados de lo que sucedía en España pero ésta se habia convertido en un motivo de enfrentamiento en todo el mundo. Los católicos norteamericanos, cuya influencia no era tan grande como para cambiar la posición generalizada de la opinión pública, jugaron, sin embargo, un papel de importancia para evitar que fuera revocado el embargo del comercio de armas con España ${ }^{16}$.

En las últimas semanas de la guerra civil Roosevelt pensaba ya que la política seguida había sido "un grave error»: así se lo dijo a Bowers y a los miembros de su gabinete. Pensaba ya que la mejor política debiera haber sido vetar tan solo el transporte de municiones a los beligerantes.

14 Guttmann, Allen, The wound in the heart. America and the Spanish civil war. New York, The Free Press of Glencoe, 1962, 292 págs 438.

is Morgan, Ted, FDR. A biography. New York, Simon and Schuster, 1985, 830 págs.,

${ }^{16}$ VALAIK, John David, “In the days before ecumenism: American catholics, antisemitism and the Spanish civil war", "Journal of Church and State, 1971, 13 (3), págs. 465-477, y "American catholics dissenters and the Spanish civil war", en Church History Review, LIII, núm. 4, I, 1968, págs. 537-555. 
Esta insatisfacción se aprecia en la tardanza en el reconocimiento de Franco. Sólo en febrero de 1939, cuando ya Gran Bretaña y Francia estaban a punto de establecer relaciones con él, Hull propuso a Roseevelt que se establecieran contactos con los representantes de Franco en París. La fecha del reconocimiento efectivo del Gobierno vencedor en la guerra civil fue la misma de su victoria definitiva; un dia antes, De los Ríos, el embajador republicano, se había despedido de Hull. Ese mismo día primero de abril, Eleanor Roosevelt telegrafió a su marido pidiendo que el Departamento de Estado interviniera a favor de los republicanos que quedaban en Madrid; su marido le aseguró que lo haría ${ }^{17}$. También lo intentó Bowers y quienes durante la guerra habian estado cerca de la causa republicana, pero en la práctica fue poco lo que consiguieron.

\section{LA SEGUNDA GUERRA MUNDIAL}

Todo cuanto antecede debe ser tenido muy en cuenta a la hora de entender la actitud de Roosevelt y de los Estados Unidos acerca de la España de Franco durante la Segunda Guerra Mundial. Hay una anécdota que merece ser citada por lo que tiene de significativa: cuando fue nombrado el primer embajador norteamericano ante el dictador español, Alexander Weddell, acudió ante Roosevelt y le preguntó si tenia algún mensaje para él. La respuesta consistió en afirmar que debia recordar que a él «no le gustaban los dictadores» ${ }^{18}$. Por supuesto, este no era un mensaje a ser transmitido en estos términos, pero expresaba una posición de fondo que es preciso tener en cuenta para entender las repetidas situaciones de tensión existente entre los dos países durante la Segunda Guerra Mundial y que tuvieron lugar muy a menudo en contra de los deseos de los propios diplomáticos norteamericanos residentes en España.

Es preciso, además, con carácter previo, hacer referencia a cuál fue la posición española durante el conflicto. En un principio, a pesar de la simpatía ideológica que Franco siempre sintió respecto de la Alemania

${ }^{17}$ FDR. His personal letters, II, pág. 875.

${ }^{18}$ BEAULAC, Willard L., Franco, silent ally in world war II. Southern Illinois University Press, 1986, 233 págs., 46. Entre las memorias de diplomáticos norteamericanos en España durante la primera etapa, véase también FEIS, Herbert. The Spanish story: Franco and the nations at war. New York, Knopf, 1948. 
de Hitler, que había sido su aliada durante la guerra civil, España fue netamente neutral. En esa primera parte de la guerra estuvo muy próxima a Italia; no entendía la alianza entre Hitler y Stalin y, además, sus intereses estaban muy lejos a Polonia. La situación, sin embargo, cambió de manera decisiva en el verano de 1940 cuando Francia fue derrotada; respecto de ella se dirigían la mayor parte de las reivindicaciones territoriales españolas que ahora podian verse realizadas y, además, Italia ya se había convertido en beligerante. La España de Franco entonces optó por convertirse en no beligerante, una fórmula que podía ser, como en el caso citado, un antecedente de la intervención en la guerra. De hecho, Franco se ofreció para hacerlo antes de sufrir cualquier tipo de presión por parte de Hitler. La "tentación española» duró tan sólo unos meses, hasta fines de 1940, pero no concluyó en la beligerancia. Probablemente la razón fundamental residió en el escaso y poco duradero interés de Hitler por una estrategia mediterránea, en especial si le enajenaba la colaboración de la Francia de Vichy. Las crecidas reivindicaciones de Franco, la desastrosa situación económica española, la ineficiencia del ejército y las profundas discrepancias, en el seno de su régimen, entre los sectores militares conservadores y la Falange fascista son otros tantos factores que contribuyeron a explicar la marginación española respecto del conflicto. Sin embargo, a lo largo de él, Franco siguió manteniendo una posición claramente cercana al Eje desde el punto de vista ideológico, y además, le prestó bases para el aprovisionamiento de sus submarinos y aviones. En no pocas ocasiones pareció inmediata la intervención de Franco en el conflicto ${ }^{19}$. Ante esta eventualidad la posición británica siempre fue idéntica. Para Churchill siempre tuvo el mayor interés que España mantuviera su neutralidad: aunque en algún momento pensó en ocupar las Canarias y siempre tuvo una profunda desconfianza respecto de Franco, en unión del mando militar pensó que era mejor procurar conservar a España fuera del conflicto, pues ello implicaría menos riesgos en una situación extremadamente delicada. Para ello, dispuso de dos armas principales. La primera y más importante consistía en facilitar o dificultar el comercio exterior de una España hambrienta de acuerdo con su comportamiento. Además, Hoare, el embajador británico, procuró fomentar la posición disidente entre los militares monárquicos.

19 Acerca de la posición española ante el conflicto ver especialmente MARQuINA, Antonio, España en la politica de seguridad occidental. Madrid, Ediciones Ejército, 1986, 1002 págs.; Tusell, Xavier, y García QueIPo de Llano, Genoveva, Franco y Mussolini. La politica española durante la Segunda Guerra Mundial. Barcelona, Planeta, 1985, 300 págs. 
Todo cuanto antecede debe ser muy tenido en cuenta para explicar la posición de los Estados Unidos de Roosevelt frente a la España de Franco durante la Segunda Guerra Mundial ${ }^{20}$. Hubo, de la misma manera que durante la guerra civil, diferencias de matiz importantes entre los diplomáticos norteamericanos y el propio Departamento de Estado. Uno de los primeros, Beaulac, ha llegado a definir la posición de Franco como la de un "aliado silencioso" que habría frustrado, con la ayuda del aprovisionamiento aliado, las pretensiones del Eje respecto de su participación en la guerra. Este es un caso extremo de simpatía por Franco, pero, en general, los diplomáticos norteamericanos en España fueron conscientes de que se podria influir sobre la posición española a través del comercio exterior, tal y como sugerian los británicos. En cambio, en los Estados Unidos predominaba la profunda antipatía hacia el régimen de Franco y por ello se sentía la tentación de imponerle actitudes netamente neutralistas 0 condenarle a la asfixia económica por procedimientos taxativos. El propio Hull asegura en sus memorias que "nunca fuimos amigos del régimen de Franco y yo lo creia malo para España y para el mundo", pero dice también que la insatisfacción que sintió ante su comportamiento fue menor que la que padeció Hitler por su negativa a intervenir en la guerra ${ }^{21}$. Pero Hull no era ni mucho menos el más drástico de los dirigentes norteamericanos respecto de Franco: a fin de cuentas él vio también aspectos positivos en el mantenimiento de la neutralidad española, mientras que Wallace e Ickes se mostraron partidarios incluso de invadir España antes del desembarco en el Norte de África. La posición de Roosevelt respecto de Franco debió resultar influida por estas tres ya mencionadas, pero sobre todo por las dos últimas. La mejor prueba de ello reside en lo tardiamente que los Estados Unidos se plegaron a la posición británica, y en las ocasiones en que se produjeron enfrentamientos entre los dirigentes de la diplomacia franquista y los norteamericanos, que fueron mucho mayores que los que tuvieron lugar con los representantes de la diplomacia británica.

Como sabemos el primer embajador norteamericano ante Franco fue Alexander Weddell ${ }^{22}$. Dadas las instrucciones recibidas por Roosevelt no

${ }^{20}$ Sobre esta cuestión, con carácter general, véase W. CORTADA, James, Relaciones España-USA, 1941-1945. Barcelona, DOPESA, 1973, 203 págs.; DurA, Juan, US policy toward dictatorship and democracy in Spain. University of California, Berkeley, Ph. D., 1979; HALSTEAD, C. R., Spain, the powers and the second world war, University of Virginia Ph. D.. 1962, 485 págs.; W. BERT, Allan, American diplomacy and Spain during world war II. George Washington Ph. D., 1975.

2) The Memoirs of Cordell Hull, I, pág. 881 y II, pág. 1334.

${ }^{22}$ Sobre esta etapa R. HALSTEAD, Charles, "Diligent diplomat: Alexander W. Weddell as 
se podia esperar que encontrara una situación especialmente propicia para establecer unas relaciones estrechas: aunque se mantenian vínculos comerciales entre los dos países existían, aparte de las discrepancias políticas, conflictos económicos derivados de la nacionalización de la Compañía Telefónica. El primer intento de acercamiento se produjo por parte de Franco que en los primeros meses de 1940 ya empezó a solicitar créditos norteamericanos debido a la situación agobiante de la economía española. Los británicos, que en marzo habian suscrito ya un tratado comercial con la España de Franco, convencieron, a través de su embajador, Hoare, a Weddell, de que esta era la manera de influir sobre la posición española. Weddell, sin embargo, encontró dificultades en convencer al Departamento de Estado en donde, por ejemplo, Welles, era contrario inicialmente a cualquier tipo de ayuda a una España de la que temía que entrara en la guerra. En torno a septiembre de 1940, precisamente cuando mayor era el peligro de que España abandonara su no beligerancia, las peticiones de ayuda económica por parte de los dirigentes españoles se hicieron casi desesperadas. Weddell consiguió convencer finalmente a Washington y en los primeros días de octubre, Roosevelt aprobó que llegara una ayuda humanitaria administrada por la Cruz Roja, que España se comprometía a no reexportar al mismo tiempo que se mantendría sin intervenir en el conflicto ${ }^{23}$.

El ministro español Beigbeder había utilizado las relaciones comerciales como argumento para que España permaneciera alejada de la guerra, pero fue inmediatamente sustituido por el falangista Serrano Suner y este hecho, así como la entrevista entre Franco y Hitler en Hendaya, supusieron un nuevo empeoramiento de la situación diplomática con los Estados Unidos. En una entrevista tempestuosa celebrada a finales del mes de octubre, Weddell acusó a las autoridades españolas de tolerar que en su país funcionara la censura alemana y Serrano declaró la "solidaridad" de su país con el Eje ${ }^{24}$. La poca publicidad dada a la ayuda norteamericana (que, como escribió Weddell a Roosevelt, sólo "arañaba la superficie" de las necesidades), la modificación del status de Tánger después de la ocupación militar española, los ataques de la prensa contra los Estados Unidos y los intentos de una penetración propagandística en América del Sur, especialmente a través del Consejo de

American Ambassador to Spain, 1939-1942", The Virginia magazine of History and Biography, I, 1974. La correspondencia de Weddell con Roosevelt en FDR Papers, PSF, Box 69, como también la de su sucesor.

${ }^{23}$ Frus, II, pág. 810.

${ }^{24}$ Frus, II, págs. 820-826. 
la Hispanidad, son otros tantos factores que explican el empeoramiento de las relaciones en los meses sucesivos. Los dirigentes españoles hubieran deseado que en las elecciones de 1940 hubiera triunfado un candidato más aislacionista que Roosevelt, y a veces propiciaban manifestaciones contra la Gran Bretaña que incluian entre sus destinatarios también a los Estados Unidos. Por su parte, Roosevelt pensó en mantener fuerzas navales en Europa para de alguna manera influir en el mantenimiento de la neutralidad española. Sólo la presión de Churchill consiguió que el presidente norteamericano volviera a pensar, a fines de 1940, en influir en la posición española a través del comercio. Esta política fue expresivamente descrita por Weddell como tendente a mantener a España entre el martillo de la amenaza alemana y el clavo del hambre.

De todos los modos muy poco se avanzó a lo largo de todo el año 1941. A pesar de intentarlo repetidamente, Weddell no conseguia entrevistarse con Franco porque Serrano lo impedía considerándolo como una de las prerrogativas de su cargo. Hull llegó a tener una entrevista extremadamente dura con el embajador español en Washington, aquella que lo fue más en toda su vida diplomática, según admitc en sus memorias; en ella consideró que la actitud del Gobierno español figuraba entre los países "más retrasados e ignorados" y juzgó el comportamiento de Serrano como "extremadamente ofensivo" ${ }^{25}$. La situación tendió a normalizarse en los últimos meses de 1941 a medida que disminuía el poder político de Serrano Suñer pero, como al final de ese año se produjo la intervención norteamericana en la guerra, sólo en la primavera de 1942 los Estados Unidos dispusieron de una oficina en España capaz de controlar mediante el comercio la posición española. Poco antes, como testimonio de lo pésimo de las relaciones entre los dos países, Weddell había llegado a aconsejar la toma de las Canarias por la fuerza aunque con la promesa de devolverlas.

En mayo de 1942 llegó como embajador norteamericano a España Carlton J. H. Hayes, un historiador muy conocido, liberal y católico, que no habia apoyado a Franco durante la guerra civil y que venía a ser un testimonio de la diplomacia personal de Roosevelt basada en nombramientos dependientes directamente de él ${ }^{26}$. Hayes se vio inmediatamente beneficiado por la evolución de la política interna española. Aunque la

${ }^{25}$ The Memoirs of Cordell Hull, II, pág. 1187.

${ }^{26}$ Sobre esta etapa véase R. HALSTEAD, Charles, "Historians in politics: Cariton J. H. Hayes as American ambassador to Spain, 1942-1945". Journal of Contemporary History. núm. 3, VII, 1975, pág. 383 y ss., y, sobre todo, sus memorias, Wartime mission in Spain. Toronto, Macmillan, 1945, 248 págs. 
razón estribó en la lucha interna en el seno del régimen y no en un cambio de Franco respecto de la Guerra Mundial, el cambio ministerial de septiembre de 1942 supuso la sustitución de un falangista como Serrano por un militar conservador y católico como Jordana. Este cambio fue interpretado por el nuevo embajador como un testimonio de que la España franquista se movia "lentamente pero con seguridad de la Falange al Ejército y de la ficción de la no beligerancia al hecho de la neutralidad real», según escribió a Roosevelt. Su posición, siempre simpatizante con Jordana, acabó por convertirse también en partidaria del régimen franquista. En sus memorias interpreta que el régimen español no era una dictadura fascista, sino una coalición conservadora; su consejero y segundo personaje en la embajada, Beaulac, era todavía más profranquista. Uno y otro no quisieron intervenir en la politica española, a diferencia de Hoare, y recibieron críticas de la izquierda norteamericana por alguna de sus declaraciones.

El momento crucial de la embajada de Hayes en España fue el del desembarco aliado en el Norte de África. Hayes contribuyó a convencer a Roosevelt de que el desembarco no se produjera en territorio español, aunque desempeñaron un papel más importante en este sentido los mandos militares, conscientes, en especial Eisenhower, de que el ataque en posesiones españolas supondría una dispersión de recursos y sobre todo una pérdida grave de tiempo. Unos días antes del desembarco, Hayes informó que los británicos habían dado seguridades a Franco que no se produciría un ataque contra él. Atendiendo a su sugerencia en el mismo momento del desembarco, Hayes entregó a Franco una carta de Roosevelt en la que también se le daban seguridades de que el ataque no iba contra España. En realidad cartas semejantes se entregaron a Pétain o Carmona, pero la prensa española interpretó que era un testimonio de la admisión de la neutralidad mantenida hasta entonces. En realidad Franco siguió siendo simpatizante del Eje y no evolucionó en su postura, sino al ritmo de los propios acontecimientos bélicos y siempre con intervenciones proclives al fascismo por parte de la Falange. Los aliados eran conscientes de esta realidad y por ello en el momento del desembarco en África prepararon el plan "Backbone" destinado a ocupar España y el Norte de África en caso de hostilidad o de que Franco autorizara el paso de tropas alemanas. Tampoco Franco confiaba en absoluto en Roosevelt y los Estados Unidos: en abril de 1943 envió una carta al Papa, siguiendo una estrategia de procurar acentuar el aspecto católico de su régimen, en la que daba la sensación de que la política norteamericana estaba en las manos de la masonería y los judios. 
A lo largo del año citado la posición española fue evolucionando de acuerdo con la guerra; la caída del fascismo italiano, durante el verano, fue un factor importante de aceleración del proceso. El Departamento de Estado y sobre todo la opinión pública liberal norteamericana eran partidarios de practicar una política de mano dura con respecto a la España de Franco, incluso recortando drásticamente los suministros; Hayes, en cambio, era mucho más tolerante y no veía la necesidad de llevar a cabo una presión excesiva, en especial contra Jordana en el que confiaba ${ }^{27}$.

Ya en los primeros meses de 1943 los norteamericanos obtuvieron concesiones a cambio de petróleo, pero el paso más decisivo se produjo cuando a finales de 1943 un telegrama enviado al Gobierno filipino de Laurel, colaborador de los japoneses, pareció suponer su reconocimiento por parte del Gobierno español. En realidad se trataba de un grave fallo diplomático, pero no encerraba ninguna significación política importante ni indicaba una voluntad simpatizante del Japón ${ }^{28}$. Sin embargo, las autoridades del Departamento de Estado aprovecharon la ocasión para mostrar hasta qué punto repudiaban al régimen de Franco.

Sin consultar a la propia embajada norteamericana ni a los británicos, los Estados Unidos decretaron en febrero de 1944 un embargo de petróleo que duró hasta que, en mayo, el Gobierno de Franco se plegó a la mayor parte de sus exigencias. Éstas consistian en entregar los barcos italianos que estuvieran en puertos españoles, retirar la División Azul de Rusia, cerrar el consulado alemán en Tánger y reducir la exportación de wolframio a Alemania. Tan solo, por sugerencia de Churchill, el Departamento de Estado admitió un plazo para que fuera reduciéndose de manera paulatina el envio de este material estratégico. Hayes también procuró que la posición española no pareciera en exceso forzada, principalmente porque ello sólo iba en perjuicio de Jordana, el elemento más neutralista del Gobierno español de la época.

Las enseñanzas de esta primera manifestación de la política dura no fueron olvidadas por los dirigentes españoles. A lo largo de 1944 y 1945 la posición del régimen franquista se hizo benevolente, casi servil, con respecto a los aliados y, en especial, los Estados Unidos, a los que fueron concedidas incluso facilidades de aterrizaje militar. Franco (que había explicado la Guerra Mundial como resultado de dos conflictos, el

${ }^{27}$ Frus, II, págs. 729-731.

${ }^{28}$ W. CORTADA, James, "Spain and the second world war: the Laurel incident", Journal of Contemporary History, XV, núm. 4, pág. 65 y ss.; The Memoirs of Cordell Hull, II, págs. 1326-1332. 
de los aliados contra Alemania, en que era neutral, y el de Rusia contra esta última, en que simpatizaba con la primera) añadió ahora un tercer término a la comparación: en la lucha contra Japón él era partidario de los aliados. Pero esa evolución era tan rápida como insincera. A la muerte de Jordana en junio de 1944 no le sustituyó otro neutralista sino Lequerica, antiguo embajador ante Vichy y persona partidaria del Eje durante la mayor parte de la guerra. Ahora se pretendió que la España de Franco había sido neutral a pesar de las anteriores afirmaciones en contrario.

Esta evolución no convenció en absoluto a la opinión norteamericana. Desde enero de 1945 hubo propuestas para romper las relaciones diplomáticas con Franco. Cuando murió Roosevelt, en abril, según las encuestas, casi la mitad de los norteamericanos no veía la posibilidad de que su país colaborara con España y un quinto quería la ruptura inmediata de relaciones. El propio Hayes, que había dimitido como embajador, no creía que Franco pudiera durar aunque tampoco él propiciara una intervención en España. En ese ambiente se escribió el más expresivo texto de Roosevelt sobre Franco que definió la postura norteamericana ante el nuevo embajador, Norman Armour, tan sólo un mes antes de la muerte del presidente ${ }^{29}$. En ella afirmaba que el régimen español había sido ayudado por Alemania e italia en su momento inicial y había seguido su modelo; eso le hacía objeto de desconfianza de un buen número de norteamericanos que querian la ruptura de las relaciones. Sin querer intervenir en los asuntos internos españoles, Roosevelt, que recordaba la posición oficial española durante la guerra y la hostilidad de la Falange, consideraba que el carácter fascista del régimen le hacía inadmisible en la comunidad de naciones.

Esta posición era, en definitiva, la consecuencia de la actitud constante de Rossevelt respecto de Franco y su régimen. El problema decisivo e irresuelto no fue enunciarlo, sino que se tradujera en la realidad práctica. Desde la guerra civil española Roosevelt fue uno de los gobernantes de una gran potencia democrática más hostiles a Franco, como éste sabia perfectamente. Sin embargo, la neutralidad norteamericana, tal como fue imaginada, favoreció al dictador español de manera indirecta. Durante la Guerra Mundial el hecho de que Franco no hubiera tomado las armas a favor del Eje impedía una intervención militar contra él que, además, no estaba justificada desde el punto de vista estratégico ni hubiera sido imaginable desde la moral. La política esbozada por Roosevelt

${ }^{29}$ Fue publicada luego en The New York Times, 15-9-1945. 
en la carta citada sería puesta en práctica por sus sucesores, pero tampoco obtuvo éxito. En realidad se demostró que tras una guerra civil un Gobierno dictatorial decidido a perdurar sólo puede ser desplazado por otra guerra civil. Los regímenes democráticos no tienen habitualmente la capacidad ni el deseo de intervenir para provocarlas. 